\title{
Mg isotope proxy constrain both erosion and chemical weathering change in deep time
}

\author{
TIANZHENG HUANG AND BING SHEN
}

Peking University

Presenting Author: tzhuang@pku.edu.cn

How continental weathering affected evolution of Earth System in deep time was not well known because continental weathering was both affected by and influencing Earth's climate. Recovery of erosion and chemical weathering change separately in deep time is key to the question, because both erosion and chemical weathering influences Earth's climate while only chemical weathering reflects climate change. However, it is hard to trace erosion and chemical weathering change separately with existing weathering proxies. Global weathering flux, the comprehensive effect of erosion and weathering can be traced by composition of seawater, such as radiogenic $\mathrm{Sr}$ isotope. Weathering intensity, relative rate of chemical weathering and erosion can be traced by relative composition of mobile and immobile element in weathering residue, such as chemical index of alteration. $\mathrm{Mg}$ isotope proxy of siliciclastic component of sedimentary rock has been used as proxy of chemical weathering intensity, due to the preferential loss of light $\mathrm{Mg}$ isotope in weathering. With previous study of modern weathering profile, deep sea sediments from South China Sea and carbonate rock samples from two late Paleozoic sections in South China, we find that $\mathrm{Mg}$ isotope fractionation in weathering linear decrease with increase of weathering intensity shown by fraction of $\mathrm{Mg}$ loss from parent rock, which reflects less fraction of $\mathrm{Mg}$ formed secondary clay mineral with proceeding weathering. The slope between $\mathrm{Mg}$ isotope fractionation and $\mathrm{Mg}$ isotope fractionation is controlled by chemical reaction rate in weathering, which directly show how Earth's climate change influence chemical weathering. With a constant chemical reaction rate in weathering constrained by the slope, chemical weathering intensity shows the influence of local erosion change. In summary, with further understanding of $\mathrm{Mg}$ isotope fractionation mechanism in weathering, we developed a new Mg isotope proxy constraining both erosion and chemical weathering change in deep time. Chemical weathering change caused by Earth's climate is directly shown by the extent of $\mathrm{Mg}$ isotope fractionation decrease with increase of weathering intensity, providing an insight to deep time weathering and evolution of Earth System. 